\title{
Prediction of Local Concretes Compressive Strength Using the Maturity Method
}

\author{
Mohammed Ali Abdalla Elsageer*, Wisam Elhmali Mansour, Hamad Suliman Abulaaj \\ Department of Civil Engineering, Faculty of Engineering, Sirte University, Libya
}

DOI: https://doi.org/10.21467/proceedings.4.32

* Corresponding author email: drmohammedalsger@gmail.com

\begin{abstract}
This paper aims to study the maturity method to predict the compressive strength of a local concrete. This method is a non-destructive test of the concrete and can be used to know the time to remove concrete formwork. The method depends on time and the concrete temperature factor on the compressive strength of the concrete by using mathematical equations to predict the value of compressive strength. In the study two Portland Cement concrete mixtures were used, of grades C35 and C45, the compressive strength was tested at 6 hours and 1, 2, 4, 8, 16, 32, 64 days at different curing temperature $20,30,40$ and $50^{\circ} \mathrm{C}$. The concrete strength was predicted by the maturity based on the Carino and Hansen equations, also the Datum temperatures for each mixture without which the concrete gained no strength was calculated. The laboratory results were compared with the theoretical results obtained from the equations of Carino and Hansen. The value of predicted compressive strength for concretes was accurate at early ages and highest or accurate in the later ages depending on the factors of the equations used.
\end{abstract}

KEYWORDS: Compressive strength, Maturity, Datum temperatures

\section{Introduction}

Increasing cost of construction has necessitated use of accelerated construction schedules to achieve economic benefits. Contractors need to know the strength of a structure or roadway in order to meet deadlines for formwork removal, a knowledge of in-situ concrete strength can reduce construction time and cost by efficient movement of forms. Furthermore it also establishes safe time for formwork removal to avoid catastrophic failure of structures with consequent danger to human life.

The strength development of concrete achieved in structural elements will be different from the strength of specimens that cured under standard curing condition, even though they are the same mixture for the following reasons ${ }^{[1]}$ :

$>$ Differences in maturity

$>$ Differences in compaction and curing

$>$ Water and cement migration within the cast element

(C) 2018 Copyright held by the author(s). Published by AIJR Publisher in Proceedings of First Conference for Engineering

Sciences and Technology (CEST-2018), September 25-27, 2018, vol. 2 .
This is an open access article under Creative Commons Attribution-NonCommercial 4.0 International (CC BY-NC 4.0) license, which permits any non-commercial use, distribution, adaptation, and reproduction in any medium, as long as the original work is properly cited. ISBN: 978-81-936820-6-7 
The differences between the strength of concrete specimens cured under standard curing conditions and that of in-situ strength obtained even though they are the same mix make it difficult to decide whether the quality of concrete supplied to the site was of the required quality. Therefore, it is necessary to determine whether the structural element is adequately strong enough to withstand the intended loading, and allowing the contractor to remove the formwork. The methods listed below are some of the most popular and widely used methods of estimating the early-age concrete strength development during construction for formwork striking purposes ${ }^{[1]}$ :

$>$ Cured Specimens Alongside The Structure, Tables of Formwork Striking Times, Temperature Matching Curing Bath, Maturity Method, Penetration Tests, Break-Off Tests, Pull-Out Tests, Rebound-Hammer Test and Coring Test

\subsection{The Maturity Methods}

The term 'maturity or maturity index' can be defined as a 'temperature-time factor' that describes the combined effect of temperature and time on the development of concrete strength. The method developed is based on the principle that concretes cast from the same mix that have equal maturity will have equal strength regardless of their actual temperaturetime history.

The maturity method is one of the most reliable methods of assessing early-age in-situ concrete strength, particularly for fast-track construction applications. Many methods have been proposed to determine the maturity of concrete empirically ${ }^{[2,3]}$. In recent years, however, many methods have been developed based on the concept of activation energy and the Arrhenius law ${ }^{[2]}$ on the rate of reaction. This method has a wide variety of applications in the precast concrete industry that include the assessment of strength of prestressed heat accelerated concrete elements ${ }^{[2,3]}$.

Maturity method in determining the time needed for the concrete to achieve adequate strength to permit the release of the pre-stressing force.

The in-situ concrete maturity can be determined using one of the following procedures:

1. Analyzing in-situ temperature recordings using maturity functions.

2. Using electronic maturity meters.

3. Using a commercial maturity probe, which is based on the evaporation of a volatile liquid.

The maturity index is determined from the temperature history of concrete by a maturity function; such as the Nurse-Saul or the Arrhenius formulation proposed by Freiesleben Hansen and Pedersen ${ }^{[2]}$. Once the maturity index or the equivalent age at a reference temperature, is determined the strength development of concrete cured at other than reference or standard curing temperature can be determined as well.

The index maturity of concrete at standard curing temperature; can then be used to determine the strength of concrete using the strength-maturity correlations of concrete cured at standard temperature. The strength-maturity correlations is developed by statistically analyzing the

Proceedings of First Conference for Engineering Sciences and Technology (CEST-2018), vol. 2 
Prediction of Local Concretes Compressive Strength Using the Maturity Method

strength data of cubes, which are cast from the same mix and cured isothermal at the reference temperature. The maturity testing procedure is described in Figure (1).

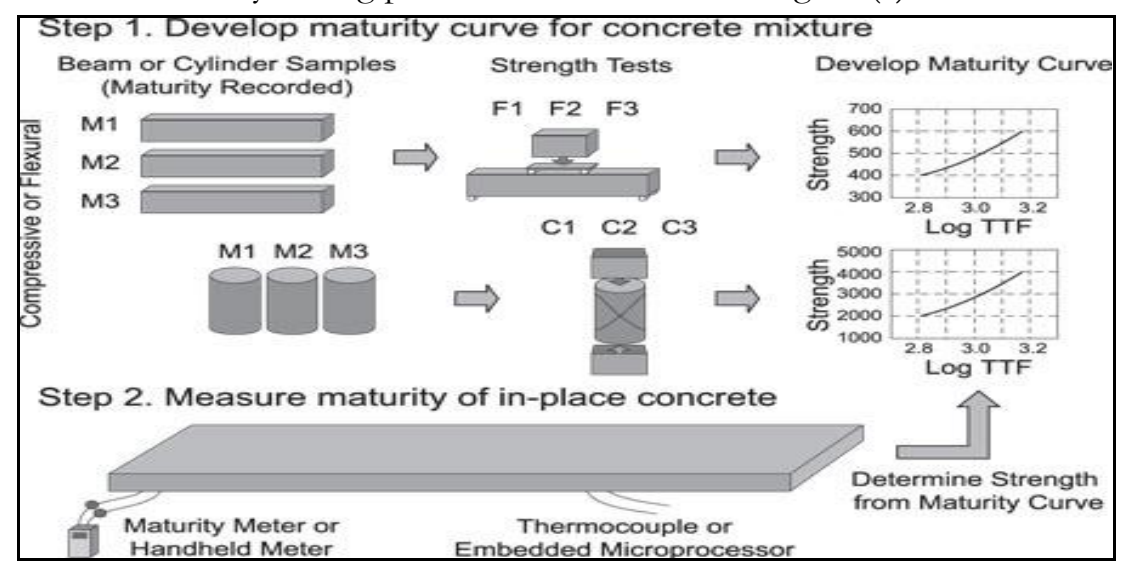

Figure (1): Maturity testing procedure ${ }^{[2]}$

The Maturity method saves time and money by the accurate prediction of concrete strength to remove formworks, cut and saw timing and open pavement to traffic. This method saves money by reducing the samples required to test. The strength of concrete estimation is also important to the new construction of buildings and roads. Maturity is useful for operating timing of pre-stressed concrete. The method can estimate the strength of concrete at any age. The negative side of the maturity method is that a complete hydration should continue without ceasing otherwise predictions will be incorrect. This method will not take into account some field actions, like inadequate vibration and insufficient curing. Every mixture has its own unique maturity. So strength maturity curve should be established for every individual mixture ${ }^{[2,3]}$.

The equations used to predict the strength are based on Nurse-Saul maturity below:

$$
M=\sum_{0}^{t}\left(T-T_{0}\right) \Delta t
$$

Where:

$M=$ Maturity index, ${ }^{\circ} \mathrm{C}$-hours (or ${ }^{\circ} \mathrm{C}$-days),

$T=$ Average concrete temperature, ${ }^{\circ} \mathrm{C}$, during the time interval $\Delta t$,

$T_{0}=$ Datum temperature (usually taken as $-10^{\circ} \mathrm{C}$ ),

$t=$ Elapsed time (concrete age in hours or days),

$\Delta t=$ Time interval (hours or days).

\section{The Strength-Maturity Relationship Proposed by Carino}

Carino'S Strength- Time Relationship

$$
S=S_{\infty} \frac{K_{T}\left(t-t_{0}\right)}{1+K_{T}\left(t-t_{0}\right)}
$$

Where:

$\mathrm{S}_{\infty}=$ Limiting strength, $\mathrm{N} / \mathrm{mm}^{2}$

$\mathrm{t}=$ Age, hours

$\mathrm{K}_{\mathrm{T}}=$ Rate constant is equal to Arrhenius equation: 


$$
K_{T}=A e^{\left[\frac{-E}{R T}\right]}
$$

Where:

$\mathrm{A}=\mathrm{A}$ constant

$\mathrm{E}=$ Activation energy, $\mathrm{J} / \mathrm{gmol}$

$\mathrm{R}=$ Universal gas constant, $8.3144 \mathrm{~J} / \mathrm{gmol}-\mathrm{K}$

$\mathrm{t}^{0}=$ Age when strength gain begins, hours

The parameters $S \infty, K_{T}$ and $t^{0}$ in equation (2) are determined by best-fit curve fitting to strength vs. age data obtained by experiential tests to a concrete cured at different constant temperature. Moreover, the equation is used to determine concrete datum temperature and activation energy ${ }^{[5]}$, which will be discussed in the activation energy section.

In 1982, Knudsen ${ }^{[6]}$, earlier than Carino, devised a similar equation to represent the degree of hydration of cement rather than concrete strength.

\section{Carino'S Strength- Maturity Relationship:}

$$
S=S_{\infty} \frac{K\left(M-M_{0}\right)}{1+K\left(M-M_{0}\right)}
$$

Where:

$\mathrm{S}_{\infty}=$ Limiting strength, $\mathrm{N} / \mathrm{mm}^{2}$

$\mathrm{M}=$ Maturity, ${ }^{\circ} \mathrm{C}$-hours

$\mathrm{K}=\mathrm{A}$ rate constant

$\mathrm{M}_{0}=$ Maturity when strength gain begins, ${ }^{\circ} \mathrm{C}$-hours

\section{Freiesleben Hansen and Pedersen Strengh-Maturity Relationship ${ }^{[7,8]}$}

The equation is a Three Parameter Exponential (TPE) and was proposed in 1985[2], based on the assumption that the strength development should be similar to the curve and relationships of heat of hydration. The Freiesleben Hansen and Pedersen is as follows:

$$
S=S_{\infty} e^{-\left(\frac{\tau}{M}\right)^{\alpha}}
$$

Where:

$\mathrm{S}_{\infty}=$ Limiting strength, $\mathrm{N} / \mathrm{mm}^{2}$

$\mathrm{M}=$ Maturity index,${ }^{\circ} \mathrm{C}$-hours

$\tau=$ Characteristic time constant

$\alpha=$ Shape parameter

Note that changing the value of the time constant preserves the same general shape of the curve while shifting it to the left or right. According to Carino changing the value of the shape parameter alters the shape of the curve in such a way that when $\alpha$ increases then the curve has a more pronounced $\mathrm{S}$ shape.

Proceedings of First Conference for Engineering Sciences and Technology (CEST-2018), vol. 2 
Prediction of Local Concretes Compressive Strength Using the Maturity Method

In 1977, Freiesleben Hansen and Pedersen ${ }^{[7]}$ proposed an equivalent age function to compute a maturity index from the recorded temperature history of the concrete based on the well known Arrhenius equation. The earliest mention of the use of the Arrhenius equation, to describe the effects of temperature on the early rate of hydration of cement, was in 1962 by Copland et al[9].

The nonlinear proposed function is as follows:

$$
t_{e}=\sum_{0}^{t} e^{\frac{-E}{R}\left[\frac{1}{273+T}-\frac{1}{273+T r}\right]} \Delta t
$$

Where

$t_{e}=$ The equivalent age at the reference temperature,

$\mathrm{E}=$ Apparent activation energy, $\mathrm{J} / \mathrm{mol}$,

$\mathrm{R}=$ Universal gas constant, $8.314 \mathrm{~J} / \mathrm{mol} \mathrm{K}$,

$\mathrm{T}=$ Average absolute temperature of the concrete during interval $\Delta \mathrm{t}$, Kelvin, and

$\mathrm{T}_{\mathrm{r}}=$ Absolute reference temperature, Kelvin.

\subsection{Aims and Objectives}

The main aim of this paper is to estimate strength development of concrete using the maturity method.

\section{Experimental Work}

To obtain normal strength concrete of target mean strengths of C35 as classified by European standard BS EN 206-1:2000, the proportions were obtained using the BRE method (mix design of normal concrete) ${ }^{[10]}$. The mix percentage of the material are shown in Table1.

Table (1): Mix Percentage of The Material to be Used C 35

\begin{tabular}{||l|l||l||l||}
\hline \hline Cement & Water & sand & Coarse aggregate \\
\hline \hline 1 & 0.549 & 1.346 & 2.617 \\
\hline
\end{tabular}

The strength development under $20,30,40$ and $50^{\circ} \mathrm{C}$, and were investigated.

\section{Materials}

All the materials used in all parts of this same study mentioned in detail and will respond as follows:

\subsection{Cement}

Portland cement type I class $42.5 \mathrm{~N}$ was used in this study. The cement was supplied by Zliten Factory.

\subsection{Aggregate}

\subsubsection{Coarse Aggregate:}

The coarse aggregate used was graded aggregate comprise crushed dolerite stone with a nominal size ranging from 5 to $20 \mathrm{~mm}$. Sieve analyses were carried out in accordance with BS 882:1992[11], in order to check whether the size distributions of the aggregate satisfy the limits 
required in the standard. The sieve analysis test of aggregates was done on each size alone (20, 10) $\mathrm{mm}$, both sizes of aggregate were mixed (The mixing ratio is $50 \%$ for each size) to improve the concrete mix, The sieve analysis test of the mixed aggregates was matching specifications.

\subsubsection{Fine Aggregate}

Natural sand from Sirte has been used. The sieve analysis test of fine aggregates was done on natural sand and fine aggregate up to $5 \mathrm{~mm}$, both sizes of aggregate were mixed to improve the mix although each of them was matching specifications. The mixing ratio is $30 \%$ size $5 \mathrm{~mm}$ fine aggregate $\& 70 \%$ sand. the sieve analysis results was matching specifications.

\section{Curing}

After casting, the concrete specimens were wrapped in cling film then submerged in water tanks set at 30,40 and $50{ }^{\circ} \mathrm{C}$ curing conditions. Except for $20^{\circ} \mathrm{C}$ as the lab temperature was $20 \pm 2{ }^{\circ} \mathrm{C}$. The specimens were covered with damp hessian and plastic sheeting, the next day, i.e. 24 hours after casting, the specimens were demoulded and placed back in their initial curing conditions up till the time of testing.

\section{Experimental Results and Data Analysis}

\subsection{Strength Development Concrete at Different Curing Temperatures}

The strength development under $20,30,40$ and $50{ }^{\circ} \mathrm{C}$ curing regimes for concretes, with strength error bars based on three replicate samples is shown in Figure (2). At an early age the strength development of the concrete at high curing temperatures is greater than at low curing temperatures. This is attributed to an increase in the hydration reaction rate. However, at a later age, the strength achieved at high curing temperatures was reduced. The strength development under $20,30,40$ and $50{ }^{\circ} \mathrm{C}$ curing regimes will be used to determine the activation energy and datum temperature of the concrete under investigation according to the ASTM C1074.

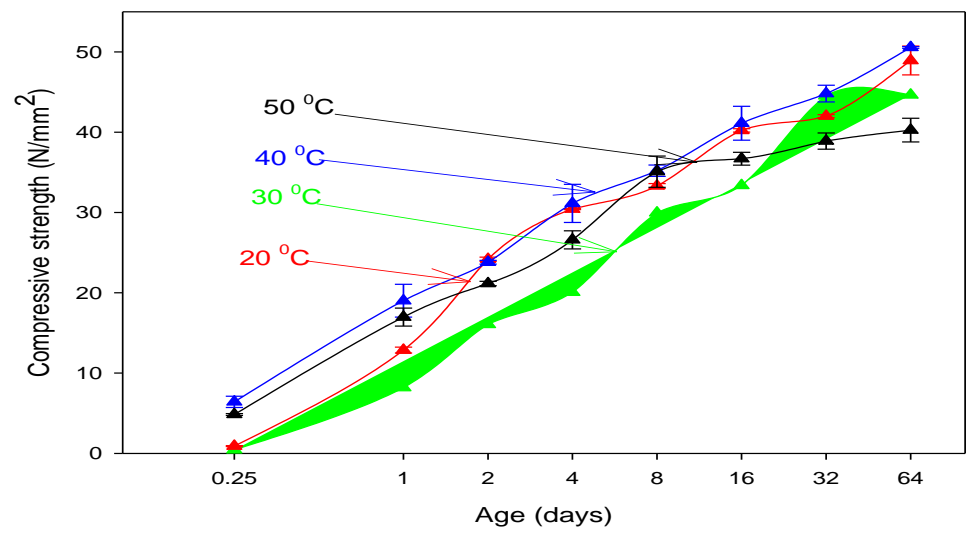

Figure (2): Compressive Strength for C35 Concrete 
Prediction of Local Concretes Compressive Strength Using the Maturity Method

\subsection{Estimation Compressive Strength by The Maturity Method}

The maturity method can be used to predict compressive strength of any concrete structural element. In this study slab of grade C 35 was cast, the slab size was 35 x 35 x $25 \mathrm{~cm}$ and cured outdoors in order to simulate behavior of concrete in-site. The temperature history of the slabs was recorded in order to use to predict the compressive strength by the maturity method. Beside that the actual compressive strength was measured using concrete cubes cured close to slabs, the compressive strength measured from the age of 6 hours up to 64 days.

\subsection{Recording The Concrete Temperature}

The temperature history of the concrete slab was measured and recorded by a digital thermometer UT321, thermocouple were put inside the concrete in the time of casting and the device was connected to the computer to record the temperature automatically. The recording was to the duration until the slab temperature become the same as the air temperature. Figure (3) shows the temperature history of the slab.

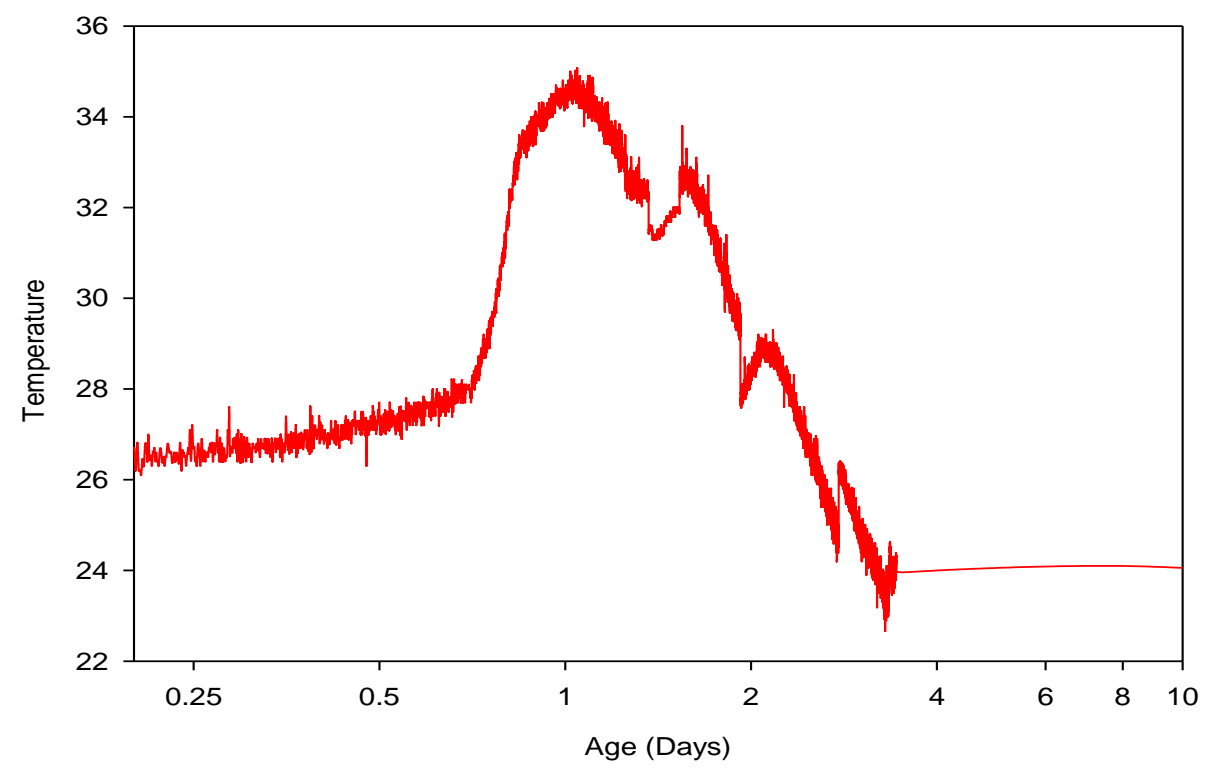

Figure (3): Temperature History of The Slab

\subsection{The Use of Maturity Functions to Predict Concrete Strength Development}

The temperatures histories were converted into predicted strength development, using Carino equation and the Three Parameter Equation (TPE) suggested by Freiesleben Hansen and Pedersen equation. Predicted strengths were then compared with the actual strength of cubes cured in order to investigate the accuracy of the equations.

A summary of the stages used to predict the strength of the concretes:

o Determine the activation energy and the datum temperature. 
o Determination of model parameters for maturity functions, Strength-age parameters based on the Carino's equation and the Freiesleben Hansen and Pedersen equation for concrete cured under standard 20 oC conditions.

The parameters $S \infty, k$ and $t_{0}$ of Carino's equation and $S \infty, \tau$ and $\alpha$ of the Three Parameter Equation suggested by Freiesleben Hansen and Pedersen for the Arrhenius equivalent age function, producing the best fit for the experimental data at standard $20{ }^{\circ} \mathrm{C}$, have been calculated. The regression analysis values are listed in Tables (2), and (3) for the concrete grades of 35 .

\section{- Carino Equation :}

Table (2): Parameters Based on Carino Equation (Strength-Age Relationships)

\begin{tabular}{|l|l||}
\hline \hline Parameters & $20{ }^{\circ} \mathrm{C}$ \\
\hline \hline $\mathrm{S}^{\infty}(\mathrm{N} / \mathrm{mm} 2)$ & 44.6443 \\
\hline \hline $\mathrm{k}$ (days-1) & 0.2000 \\
\hline \hline $\mathrm{t}^{0}$ (days) & $1.4832 \mathrm{E}-016$ \\
\hline \hline $\mathrm{R}^{2}$ & 0.9819 \\
\hline
\end{tabular}

\section{- Hansen Equation :}

Table (3): Parameters Based on Hansen Equation (Strength-Age Relationships)

\begin{tabular}{||l|l||}
\hline Parameters & $20{ }^{\circ} \mathrm{C}$ \\
\hline \hline $\mathrm{S} \infty \mathrm{N} / \mathrm{mm} 2)$ & 55.5283 \\
\hline \hline $\boldsymbol{\tau}$ (days) & 3.4769 \\
\hline \hline a & 0.5500 \\
\hline \hline $\mathrm{R} 2$ & 0.9931 \\
\hline
\end{tabular}

\section{Note:}

o Carino (NS) means that the strength-maturity relationship that has been described by Carino with maturity calculated according to the Nurse-Saul equation is used.

o Carino (Arh) means that the strength-age relationship that has been described by Carino with equivalent age calculated according to expression suggested by Freiesleben Hansen and Pederson using the Arrhenius equation is used.

o Hansen (NS) means that the strength-maturity relationship that has been described by Freiesleben Hansen and Pederson with maturity calculated according to the Nurse-Saul equation is used.

o Hansen (Arh) means that the strength-age relationship that has been described by Freiesleben Hansen and Pederson with equivalent age calculated according to expression suggested by Freiesleben Hansen and Pederson using the Arrhenius equation is used.

The activation energy and datum temperature determined according to the ASTM C1074, the datum temperature value is $5.5^{\circ} \mathrm{C}$ and the activation energy values determined from the two methods (ASTM standard and TPE) as in Table 4.

Proceedings of First Conference for Engineering Sciences and Technology (CEST-2018), vol. 2 
Prediction of Local Concretes Compressive Strength Using the Maturity Method

Table (4): Apparent Activation Energy Based on Carino and TPE Methods

\begin{tabular}{|c|c|}
\hline \multicolumn{2}{|c|}{ Activation energy $(\mathrm{kJ} / \mathrm{mol})$ based on } \\
\hline Carino method & TPE method \\
\hline 15.84 & 30.06 \\
\hline
\end{tabular}

Figure (4) shows that the only function predict the strength quit well up to age of 8 days is Carino (Arh), at later ages the strength over estimated. The other function predict the strength well up to the age of 1 day only and overestimated the strength for the other ages.

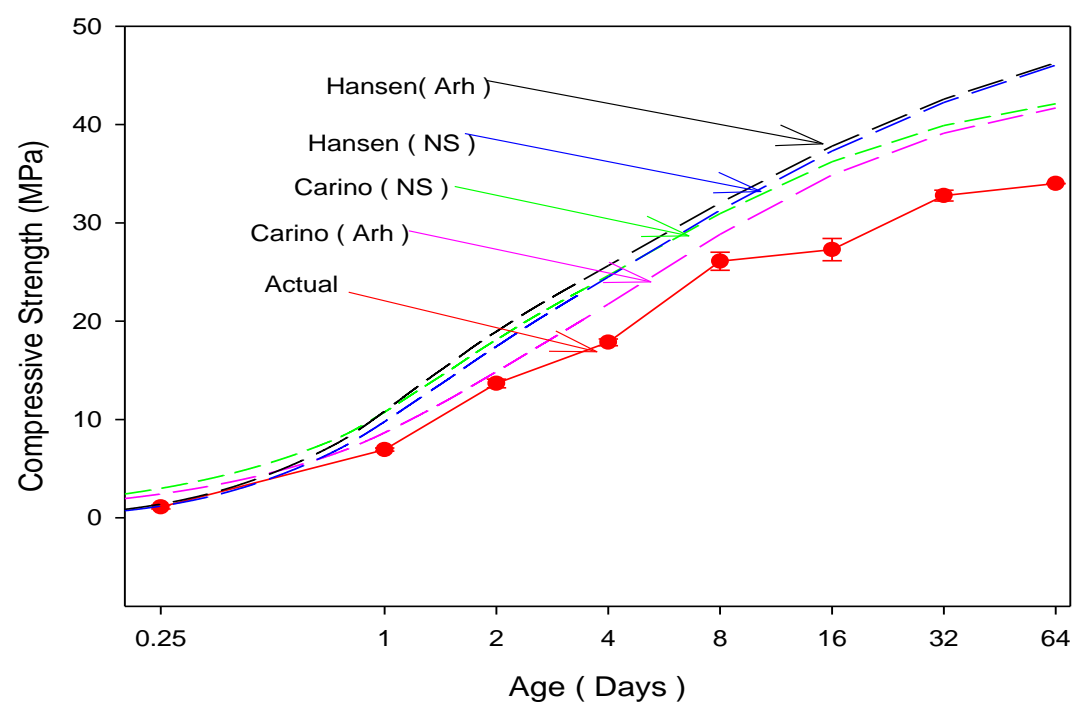

Figure (4): Predicted Compressive Strength Based on The Carino and TPE Equation.

Changing the values of datum temperature in the maturity equation between the determined values $5.5^{\circ} \mathrm{C}$ and recommended values by the standard that $-11{ }^{\circ} \mathrm{C}$, shows that Hansen (NS) function accurately predict the strength up to 8 days. The other equation overestimated the strength at all ages as shown in figure (5).

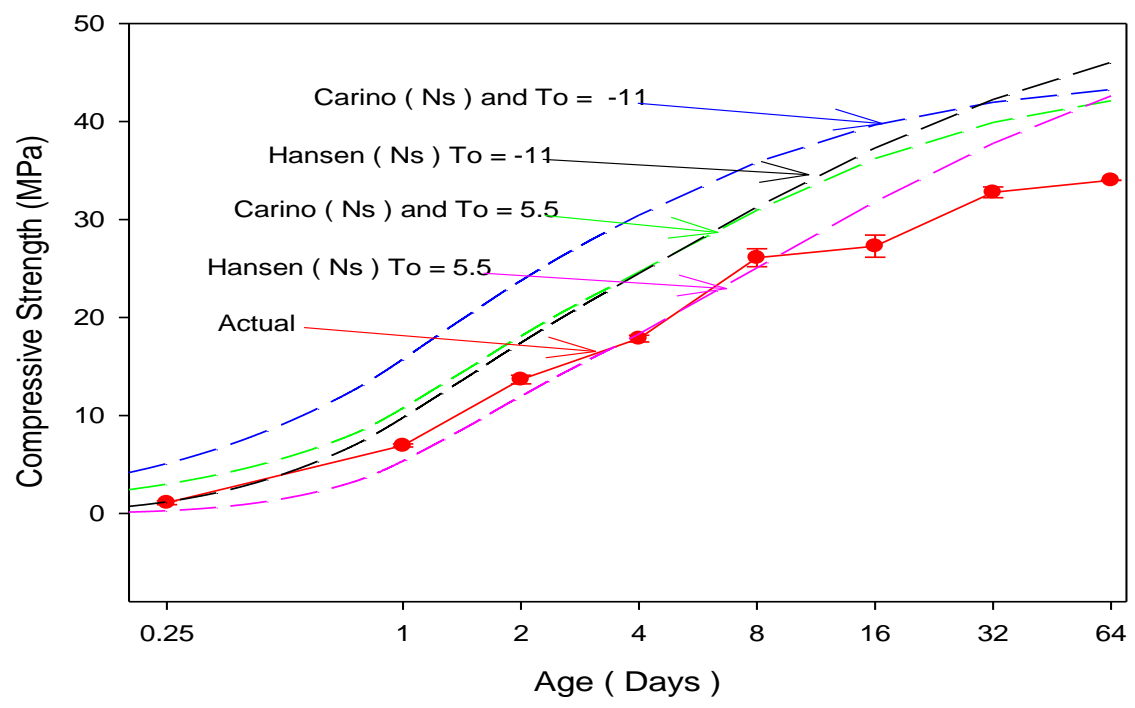

Figure (5): Predicted Compressive Strength Based on The Carino and TPE Equation. 


\section{Conclusions}

Based on the results of this study, the following conclusions are drawn:

At early age (1- 4 days) the strength development under $20,30,40$ and $50^{\circ} \mathrm{C}$ curing regimes for the concrete cubes increases as the temperature increase. From the age of 8 to 64 days the strength development the strength development decreases as the temperature increase

$>$ The study has shown that Carino (Arh) function is able to predict the compressive strength with sufficient accuracy up to the age of 8 days.

$>$ The study has shown that equation Hansen (NS) considered very accurate to predict the compressive strength using determined datum temperature up to the age of 8 days.

\section{Acknowledgment}

First and foremost, we thank Allah. This paper based on undergraduate project during the Academic year 2013/2014 done by the students, Ahmed Mohammed Emsilkh, Ali Nurie Emhlhel, Abdullah Mansour Emhemed and Wisam Elhmali Mansour under the supervision of Dr. Mohammed Ali Abdalla Elsageer

The authors are gratefully and sincerely thank the students for their hard work on the experimental and theoretical parts of the project.

Special thanks are due to Mr. Ahmed and Mrs. Haw the technicians in the concrete lab for their assistance with the laboratory work.

\section{References}

[1] Newman, J. B. and Choo, B. S., Advanced Concrete Technology, Volume 2: Concrete Properties 2003: Elsevier Science \& Technology.

[2] Malhotra, V. M. and Carino, N. J., Handbook on nondestructive testing of concrete 2004: ASTM International.

[3] Carino, N. J. and Lew, H. S., The maturity method: From theory to application. Cement, Concrete, and Aggregates, 1984. 6(2): p. 61-73.

[4] Association, American Concrete Pavement, Maturity testing of concrete pavements: Applications and benefits. Publication IS257P, 2002.

[5] ASTM C 1074, Standard Practice for Estimating Concrete Strength by the Maturity Method," Annual Book of ASTM Standards, 2004.

[6] Geiker M. and Knudsen T., Chemical Shrinkage of Portland cement Pastes. Cement and Concrete Research, 1982. 12(5): p. 603-610.

[7] Hansen, P. F. and Pedersen, E. J., Maturity computer for controlled curing and hardening of concrete, 1977.

[8] Hansen, P. F. and Pedersen, E. J., Curing of concrete structures 1984.

[9] Copeland, L. E., Kantro, D. L., and Verbeck, G. J., Chemistry of hydration of Portland cement 1960: Portland Cement Association, Research and Development Laboratories.

[10] Teychenne, D., R. Franklin, and H. Erntroy, Design of normal concrete mixes, Vol. 2.1997: BRE (Building Research Establishment UK). 46.

[11] BSI, BS 882:1992 specification for aggregate from natural sources for concrete 1992, BSI-British Standards Institution. 